\title{
0 Brasil nas Obras de Pero Gândavo e Richard Hakluyt
}

\author{
Bianca Batista
}

Luiz Montez

$(\mathrm{UFRJ})^{*}$

\section{Introdução}

Mas quem eram, afinal, esses construtores do Brasil na Europa? Em que condições e com que intuito passaram pelo país? Que parte dele tiveram diante dos olhos? Quando e onde publicaram seus livros? Para quem escreviam? Que alcance tiveram os seus escritos? (Jean Marcel França, A Construção do Brasil na Literatura de Viagem, 2012)

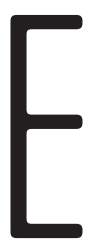

ssas perguntas elencadas pelo pesquisador Jean Marcel França nortearam nosso interesse acerca da construção discursiva do Brasil nas obras do gramático-cronista Pero Magalhães de Gândavo, História da Província de Santa Cruz que vulgarmente chamamos Brasil (1576) e do clérigo-editor Richard Hakluyt, The Principal Navigations, Voyages and Traffiques of the English Nation (1589-1600). Ao longo do período escolar, aprendemos que a presença estrangeira no Brasil colonial esteve restrita às tentativas de colonização francesa e holandesa, e que os ingleses tiveram atuação efetiva na região apenas no período monárquico.

* Universidade Federal do Rio de Janeiro. 
Nossa proposta é demonstrar que os ingleses também tinham interesse em explorar as riquezas locais e tomar posse desta região no século XVI e, em virtude disso, investigamos a história inglesa sobre o Brasil apagada do nosso passado histórico. A publicação de relatos, sua supressão, dentre outros fatores, envolveu questões políticas e ideológicas em um cenário de intensas disputas pelos territórios do Novo Mundo, em especial o Brasil, uma região que não fora de imediato ocupada efetivamente pelos portugueses depois da sua descoberta.

Também proponho contestar conceitos cristalizados de que a obra de Richard Hakluyt é "the prose epic of the modern English Nation"; (Froude 1852) e que a obra de Gândavo é uma "propaganda de emigração", (Abreu 2008) "literatura de informação" (Bosi [1936] 2006) e literatura de "cunho edênico". (Holanda 2000) Por mais que o cronista-gramático afirme no paratexto que a província seria um "amparo" para "todos aqueles que nestes reinos vivem em pobreza", sua obra não se restringe a ser uma "propaganda" para que os pobres pudessem viver em um "paraíso terrenal". Há questões de cunho ideológico envolvidas na produção destas obras que não estão totalmente "visíveis" nos paratextos e no texto.

Acreditamos que o espaço temporal em que estas obras foram organizadas e impressas, 1576,1589-1600, e o contexto político em questão, contestação do Tratado de Tordesilhas e disputa pelas terras do Novo Mundo, motivaram Pero Gândavo e Richard Hakluyt a publicarem estes livros, assim como determinaram a escolha dos verbos, nomes e adjetivos no título das obras, no título das seções e, principalmente, a projeção de quem eram os principais atores da história do Brasil e o papel a ser assumido pelos seus reinos nesta região.

Em sua pesquisa acerca da teoria da recepção, Hans Robert Jauss (1979[1994]) afirma que a experiência do leitor no mundo e da sociedade das letras em um dado tempo histórico confere dinamicidade ao texto, i.e., o leitor traz consigo um "mundo vivencial" que é acionado na leitura do texto, tornando-o coparticipante do sentido do texto e o principal responsável pela sua circulação em uma determinada sociedade. Baseados nisso, acreditamos que as notícias sobre a província 
interpretadas por Pero Gândavo e Richard Hakluyt, em conjunto com suas intenções político e ideológicas no cenário de disputa pelas Américas, determinou as diferentes histórias sobre o Brasil nestas obras.

Pautados nas perguntas "Por que escreviam?" e "Para quem escreviam?", daremos início a nossa investigação sobre os motivos políticos e ideológicos que levaram diversos sujeitos, em especial, o cronista-gramático português e o clérigo-editor inglês a apresentarem a província sob diferentes viés e a assumirem a tarefa de escrever sobre esta região do Atlântico Sul sem necessariamente "terem visto o mar [e os sujeitos] sobre o qual escreveram." (Popelinière apud Delmas 2011, 3)

\section{História da Província de Santa Cruz que vulgarmente chamamos Brasil}

O cronista português defende o nome Santa Cruz dada a associação entre a região e o colonizador católico. A defesa do nome correto ao invés do nome vulgar é uma das propostas de Pero Gândavo e, por isso, há a substituição do nome Brasil pelo nome Santa Cruz, de Terra para Província e, consequentemente, uma mudança no nome dos livros, de Tratado da Terra do Brasil (1570 [1826]) passa a História da Província de Santa Cruz (1576).

Considerando que "a história não é uma projeção que o homem faz do presente no passado, mas a projeção de um passado que ele escolheu, uma história ficção, uma história-desejo", (Le Goff 1996, 28) acreditamos que a escrita e a publicação da história das "coisas notáveis e de grande admiração" da província envolviam dois propósitos: construir uma memória portuguesa nas Américas "que até agora [não havia] pessoa que empreendesse, havendo já setenta e tantos anos que esta província foi descoberta" (Gândavo 37) e construir um direito de posse, dado que os estrangeiros sabiam muito mais sobre a província que os próprios portugueses, "já que os estrangeiros a têm noutra estima, e sabem suas particularidades melhor e mais de raiz que nós, parece coisa decente e necessária terem os nossos naturais a mesma notícia." (38) 
A substituição de palavras no título fornece indícios acerca da intenção comunicativa do gramático-cronista. Tratado denota "estudo ou obra a respeito de uma ciência ou arte", e História "conjunto de conhecimentos relacionados com o registro cronológico e explicação de fatos do passado." (Borba 1559, 816) A palavra Terra denota "localidade, lugar, território" e a palavra Província, por sua vez, denota "região conquistada fora da Itália e administrada por um governador patrício" e "divisão regional ou administrativa de muitos países, em geral sob a autoridade de um delegado do poder central." (1535, 1289) Como podemos observar, a palavra Tratado indica que o texto é uma obra de cunho literário enquanto a palavra História aponta que o texto faz parte da trajetória expansionista portuguesa e a palavra Província aponta uma submissão política, administrativa e jurídica de um território e seus habitantes a um soberano e, com isso, um direito do mesmo de possuir e governar a região, enquanto Terra apenas aponta a existência de uma região.

No título, também ocorreu uma mudança da denominação da região, de Brasil passou a Santa Cruz. Santa Cruz foi o nome dado por Pedro Álvarez Cabral no ato da descoberta enquanto o nome Brasil era referência a uma das principais mercadorias locais, o pau-brasil, madeira de cor avermelhada utilizada para o tingimento de roupas. O nome Santa Cruz mobilizava conhecimentos socialmente construídos sobre personagens e episódios religiosos, o símbolo da morte de Cristo, o que, de certa forma, vinculava a nova terra descoberta ao catolicismo. Além desta relação nominal com o Cristianismo, a defesa do nome correto era uma forma de vincular o Atlântico Sul à situação política vigente, uma região descoberta pelos portugueses.

O gramático-cronista indica, no primeiro capítulo do livro, que o nome correto, e não o vulgar, era um elemento crucial na sua história, De como se descobriu esta província e a razão por que se deve chamar Santa Cruz e não Brasil. Como o título aponta, o nome atribuído pelo descobridor português deveria ser utilizado para se referir à província e não um nome popular atribuído por "[pessoas] não habilitadas para dar nomes às propriedades da Real Coroa." (Barros 1988 [1552], 392) A escolha do verbo modal dever aponta que a ação de chamar e 
empregar o nome Santa Cruz é considerado por Gândavo uma obrigação dos sujeitos. Segundo Maria Eugênia Duarte (2012), os verbos modais apontam as "atitudes e opiniões do falante, ou seja, tradu$z[\mathrm{em}]$ as noções de possibilidade, dever, obrigação, necessidade etc." e, no caso em questão, o verbo dever aponta a "modalidade deôntica, relacionada à obrigação e à permissão", sendo que em outros contextos sóciointercionais também pode apontar a modalidade epistêmica "relacionada ao conhecimento, à crença e à opinião ( $\mathrm{e}$, por extensão, à incerteza e à probabilidade)." (78) Em virtude disso, acreditamos que o gramático-cronista utiliza o verbo modal no presente do indicativo (deve) para ratificar que a ação de "chamar de Santa Cruz" tem a obrigatoriedade de ocorrer no tempo presente para que prevaleça socialmente o nome atribuído pelo descobridor. Caso utilizasse o modal no futuro do pretérito (deveria), o verbo apontaria apenas uma opinião sobre o nome da região recém-descoberta.

Gândavo inicia a história da província a partir da única informação que circulava entre os literários portugueses até então, a chegada de Pedro Álvares Cabral à costa brasileira em 1500. O gramático-cronista descreve o temporal que a frota enfrentou durante o percurso, que ocasionou a perda de uma das embarcações, mas que logo depois foi "reunida outra vez a frota" na "bonança" do tempo, e em um "mês navegando com ventos prósperos foram dar na costa desta província (...) parecendo a todos que era alguma grande ilha que ali estava, sem haver piloto nem outra pessoa alguma que tivesse notícia dela, nem que presumisse que podia haver terra firme naquela parte ocidental." (42) O fato dos pilotos não terem notícia e nem presumirem que a terra existia implica que não existiam relatos sobre a região, o que impossibilitava supor acerca da grande ilha que tinham avistado.

A ausência de relatos impressos portugueses sobre a região cedeu espaço para as nações concorrentes construírem sua própria história sobre o Brasil e consequentemente, um direito de posse. Utilizamos o relato do huguenote Henri Lancelot Voisin de La Popelinière para corroborar nossa assertiva: 
Les discours de ce dernier livre, vous confirmera encore mieux ce que dessus par les poures essais que la nation Françoise fit à la decouverte conqueste \& peuplade l'autre portion Americaine, dite le Bresil \& des Portugais, Tierra de Sancta Crux (...).

“(...) Les Français tousfois, Normans four tous \& les Bretons maintiennent avoir premier decouverte ces terres \& d'ancienneté traffiquer avec les sauvages du Brésil contra la riviere de Sainct Français au lieu qu'on a depuis appellé Port Real. Mais comme en autres choses mal auisez en cela, ils n'ont l'espirit ny descretion de laisser un seul escrit public (...) "Les Français seuls l'ont nommé terre du Bresil par ignorance de ce que dessus \& qu'ils y ont trouvé ces bois [couleur vermeille] (....)." (s/n)

Na sua obra Trois Mondes (1582), o huguenote Popelinière aborda as viagens marítimas realizadas desde os gregos e os romanos até às viagens ao Novo Mundo. Estas se encontravam no terceiro capítulo e tinham como principais protagonistas os franceses, os espanhóis e os portugueses. ${ }^{1} \mathrm{O}$ huguenote inicia o capítulo sobre o Novo Mundo a partir da chegada do capitão Nicholas Durand de Villegagnon ao Brasil. O rei Henri II deu ordens ao capitão Villegangnon para descobrir alguma região fora da Europa onde pudessem habitar e "viver em liberdade de consciência". A busca de uma região para fugirem das perseguições religiosas levou o capitão a "descobrir" o Brasil.

Popelinière cita a obra de André Thévet, cosmógrafo que havia publicado um livro sobre a viagem ao Brasil, Les Singularitez de la France antarctique, autrement nommée Amerique: \& de plusieurs terres \& isles decouvertes de nostre temps (1557) para corroborar a veracidade do seu discurso. Como afirma Possenti (2001 apud Curcino 1025), a referência ou citação de uma palavra no texto permite ao leitor fazer "associações mais ou menos livres entre o que lê e outros temas (...)", o que implica que o livro dialogava com obra impressas sobre esta

1. "le narré des premiers \& second livres a fait voir de quel heur les Portugais, Espagnols et Français furent assiste en la conquest des terres neuves." 
temática e com outras que surgissem posteriormente, como a obra de Jean de Lery, L'Histoire d'un voyage faict en la terre du Brésil, autrement dite Amérique (1578).

Segundo Popelinière, após a retirada dos franceses, o rei D. Manuel enviou embarcações para descobrir o Brasil, pois o monarca acreditava que Cabral havia descoberto a região, sendo que, na verdade, o capitão navegara em uma região próxima a Guiné, descobrindo, assim, Santa Cruz, e não o Brasil. Esta região também ficava ao sul do continente e era tão próspera quanto a França Antártica, "elle est à quarant cinq degrez, estat ainsi une part souz la zone torride \& l'autre sous la temperée como assure Pero de Magalhães a Dom Luis Perreira, governeur en pays de Sus (...). Est la meillure province de tout l'Amerique, ne manque de mines d'or \& d'argent". (20)

Popelinière cita um fragmento da obra de Gândavo para afirmar que uma parte do Atlântico Sul foi descoberta pelos portugueses, Santa Cruz, e a outra parte foi descoberta pelos franceses, Brasil. O huguenote lamenta que os navegantes franceses não tenham "deixado um registro público" sobre suas expedições à costa brasileira e comércio com os índios, pois estes textos comprovariam que as terras do Novo Mundo não haviam sido descobertas exclusivamente pelos ibéricos, invalidando assim, a primazia de descoberta, um dos argumentos para a divisão do mundo entre a Coroa de Castela e Avis. Caso estes textos tivessem se tornado um "registro público", os franceses poderiam restituir seu direito de colonizar o Brasil. A publicação destes textos permitiria tornar as viagens francesas conhecimento público, reconfigurando assim, o cenário político e literário em voga, de forma que, os outros navegantes [tivessem] notícia e [presumissem] que aquela "terra firme" já havia sido descrita e descoberta pelos franceses e que os portugueses estavam usurpando seu direito de posse. ${ }^{2}$

A publicação da história da província por Pero Gândavo permitiria incluí-la na memória expansionista portuguesa e com isso, contestar coletâneas de viagem como a de Popelinière que defendiam um

2. "ayant mandé au Roy Manuel [envoyé] navies à decouvert de tout le pais \& ainsi peu à peu toute cette coste fut connüe e usurpe par le Portugais." (s/n) 
direito de posse francês sobre o Brasil. O gramático-cronista defende que a escrita foi um dos elementos que determinaram a imortalidade das descobertas romanas e gregas, de forma que mesmo com o passar dos séculos, as nações europeias sabiam acerca das conquistas destes impérios.

Gândavo apresenta a escrita como um elemento diferenciador entre as nações dominadoras, gregos e romanos, e os dominados, bárbaros. Os dominadores ocupavam tal status social e político por se engajarem em "perpetuarem seu nome" enquanto os dominados eram "pouco solícitos e cobiç̧osos de honra" e, por isso, destinados a serem subjugados e terem sua "voz" apagada da história, "daí os gregos e romanos tomarem todas as outras nações por bárbaras e, na verdade, com razão lhes podiam dar esse nome, pois eram tão pouco solícitos e cobiçosos de honra que por sua mesma culpa deixavam morrer aquelas coisas que lhes podiam dar nome e fazê-los imortais." (40)

A partir desta comparação entre romanos/gregos e bárbaros, Gândavo explica que o reino português não poderia ser "pouco solícito e cobiçoso de honra" ou "deixar morrer" grandes feitos que "lhe podiam fazer imortais", pois um verdadeiro império se empenhava em imortalizar sua glória. Para que a descoberta portuguesa nas Américas se tornasse imortal e prevalecesse o nome Santa Cruz era preciso que as informações sobre a província passassem a ser de conhecimento público para que todas as nações europeias soubessem que a região do Atlântico Sul foi descoberta pelos portugueses e lhe pertencia por direito.

Gândavo estava ciente da larga produção textual sobre o Brasil na Europa, em especial nas nações concorrentes, acerca das rotas e riquezas locais. As "coisas dignas de grande admiração" da colônia não podiam continuar em uma situação de "descuido" pelo reino, elas deveriam fazer parte do discurso de descoberta portuguesa, o que tornava urgente "os nossos naturais terem a mesma notícia". Soares de Sousa corrobora a assertiva de Gândavo ao se considerar encarregado de "manifestar a grandeza, fertilidade do Estado do Brasil" visto que "os reis passados tanto se descuidaram" (5) do território brasileiro. Sousa acreditava que as riquezas do Brasil estavam em "perigo" 
em virtude do assédio das nações estrangeiras às costas brasileiras e a possibilidade de se "assenhorearem" desta província por razão de não estarem as povoações fortificadas. (6)

Segundo Sheila Hue (2014), a Coroa portuguesa inibiu a publicação de documentos referentes à província americana para evitar o assédio de nações concorrentes. Contudo, tal proibição apenas fez com que os próprios portugueses não tivessem amplo conhecimento sobre o Brasil, pois já circulavam na Europa notícias sobre o território, como, por exemplo, o relato de Hans Staden, Warhaftige Historia und beschreibung eyner Landtschafft der Wilden Nacketen, Grimmigen Menschfresser-Leuthen in der Newenwelt America gelegen; (Marburg, 1557) o relato de Ulrich Schmidel, Wahrhaftige Historie einer wunderbaren Schiffahrt; (Frankfurt,1567) o livro de André Thevet, Singularities of France Antarctique; (Paris,1557) e o relato publicado na coletânea de Giovani Battista Ramusio, Navigation del capitano Pedro Alvares Cabral res scrita un piloto Portoghese \& tradotta di lingua Portoghesa in la italian e Discorso d'un gran capitano di mare francese sobra la navigationi fatte alla Nuova Francia; Navigationi del Capitano Pedro Alvares Cabral Scrita per un Piloto Portoghese et Tradotta di Lingua Portoghese in Italiana. (Veneza, 1554)

Acredita-se que um folheto sobre o monstro marinho da capitania de São Vicente fora publicado em Portugal e a única versão portuguesa conhecida é de autoria de Brocado, Obra chamada primavera dos mínimos (1569). (Brito, 2006) Todavia, antes que a iconografia do monstro marinho fosse publicada no livro de Pero Gândavo, esta já circulava pelo continente europeu, Nel Bresil di San Vicenzo nella Citta di Santo etc.; (Veneza, 1565) Newe Zeytung von einem seltzamen Meerwunder so sich diss nechst verschinen Lxiiii Jar [im Land Bresilia bei] der Statt Santes auss dem Meer herfür gethon und daselbst von den Innwohner umbgebracht und von mennigklich ist gesehen worden. (Augspurg, 1565) Uma tradução da versão italiana foi publicada em Frankfurt e Zurique com os seguintes nomes: Newe Zeytung Von einen seltzamen Meerwunder, etc; Kampf gegen androgynes Wesen, das 1565 in Brasilien dem Meer entstiegen ist. Na Holanda, esta iconografia foi publicada no livro de Adriaen Coenen sobre peixes e baleias, Visboek e Walvishboek. (Antwerp, 1577) 
Enquanto a história da província estava "sepultada em silêncio", em "sono repousado" e "pouco sabida", em Portugal, notícias sobre o Brasil eram impressas e traduzidas nas nações europeias que visavam se inserir no cenário das grandes navegações e refutavam a divisão das Américas entre as monarquias ibéricas: "the sea and trade are common by the law of nature and of nations, it was not lawful for the Pope, nor is lawful for the Spaniard, to prohibit other nations from the communication \& participation of this law." (Hakluyt, 1598 apud Armitage, 2000 108) Gândavo sabia que o vão editorial português sobre a província cedia espaço para que outras nações construíssem sua própria história sobre provincia e tentassem estabelecer colônia, como o fizeram os franceses no Rio de Janeiro, França Antártica (1555-1560), anos depois no Maranhão, França Equinocial (1612-1615) e os holandeses no Nordeste, Nova Holanda (1630-1654): "French, English and Dutch challenged the Iberian definition of oceans as sovereign spaces (...), the new oceanic peripheries were intrinsically international arenas". (Daniels; Kennedy 2002, 235)

O engajamento discursivo de afirmar que Santa Cruz era o nome correto da província e Brasil era o termo "vulgar" e "errôneo" era uma forma defender os valores simbólicos do nome visto que as disputas por territórios do Novo Mundo também ocorriam no espaço textual, "é preciso pensar além da semântica dos nomes próprios para encarar o fenômeno de nomeação como um ato eminentemente político." (Rajagopalan 2003, 82) O apagamento do nome posto pelo descobridor português, de certa forma, apagava a intrínseca relação entre a província e a metrópole, e o nome da principal mercadoria local, pau-brasil, cedia espaço textual para que outras nações construíssem sua própria história sobre a região, como na obra de Popelinière, "la nation francaise fit a la decouvértes et conquests y peuplade la portion Americaine dite le Brésil (...) les Français sels l'ont nommée terre de Brésil." (s/n)

Na obra do cronista-gramático, o nome Brasil está vinculado ao descompromisso dos nativos com o catolicismo e o apego a um dos principais bens locais, o pau-brasil, enquanto que para o huguenote, este nome está vinculado a um direito de posse francês sobre esta 
região do Atlântico Sul, pois eles descobriram e nomearam a nova terra de Brasil. No cenário sócio-político em questão, uma das regiões da América, Brasil, é alvo de disputa entre os reinos de Portugal e França e essa disputa também se configura no cenário discursivo, sendo o signo Brasil projetado de diferentes formas pelos escritores dado suas realidades culturais, sociais e religiosas.

As diferentes projeções atribuídas a um mesmo nome provam que "a palavra está sempre carregada de um conteúdo ou de um sentido ideológico ou vivencial" (Bakhtin 2010, 114) e que os embates de poder também podem se configurar no signo linguístico, provando, assim, que os embates que ocorrem na sociedade também se fazem presente no âmbito discursivo. A palavra é uma "arena onde se desenvolve lutas", espaço de tensões e embates de poder entre sujeitos, grupos sociais e classes, "o discurso não é apenas o que traduz lutas ou os sistemas de dominação, mas é a coisa para a qual e pela qual a luta existe, o discurso é o poder a ser tomado". (Foucault 1984 apud Fairclough 2001, 77) As palavras também "[dirigem-se] a um interlocutor", "um auditório social" (Bakhtin 2012, 113) imediato ou projetado, o que implica que seu caráter ideológico está vinculado a sua interação com outros interlocutores e em virtude disso, o valor destas palavras se tornam efetivos quando direcionados para um público/auditório interacional.

Isso prova o quanto a materialidade concreta deve ser levada em consideração para se compreender os valores ideológicos atribuídos pelos sujeitos e grupos aos signos e enunciados em determinados contextos sócio-comunicativos. Esses embates de poder não implicam que a interação entre os sujeitos se configure de forma dicotômica, um certo e um errado, um vencedor e um perdedor, mas sim participantes de um diálogo em que ao mesmo tempo que são atravessados por uma teia de enunciados, eles atribuem valor a estes ao corroborar, concordar, refutar ou contestar os enunciados que os antecedem, com os quais se deparam ou projetam em um determinado contexto interacional.

Acreditamos que a escolha dos nomes são ideologicamente motivados dado que naquele contexto histórico e político os nomes das 
ilhas e províncias descobertas precisavam indicar na sua face semântica e linguística que as novas terras pertenciam a determinado reino, ratificando, assim, que "as palavras são tecidas a partir de uma multidão de fios ideológicos e servem de trama a todas as relações sociais em todos os domínios." (Bakhtin 42) Santa Cruz simbolizava o compromisso do reino com a propagação do evangelho aos gentios assim como ratificava que aquele território era propriedade portuguesa enquanto Brasil simbolizava um dos principais bens da província, o pau-brasil.

A descoberta e a ocupação em terras ultramarinas envolveram atos de posse, que consistiam na ação simbólica de erguer cruzes, na ação linguística de nomear lugares e na ação discursiva de escrever sobre as terras e nativos, "taking possession is principally the performance of a set of linguistic acts: declaring, witnessing, recording." (Greenblatt 1991, 57) Estes atos ratificavam que a região descoberta passava a ser propriedade de determinado reino, "a nomeação equivale a tomar posse (...) uma declaração segundo a qual as terras passam a fazer parte do reino." (Todorov 1999, 32) Guzauskyte $(2014,48)$ acredita que o ato de nomeação precisava contar com um público (ouvintes, leitores e escribas), pois o ato de posse para se institucionalizar precisava ser textualmente registrado para que fosse validado na sociedade letrada e principalmente, reconhecido por outros sujeitos.

A defesa do nome da província era importante para a estruturação de uma história de descoberta portuguesa no Atlântico, o nome correto ratificava o pioneirismo lusitano e a predestinação divina de que a província "fosse possuída pelos portugueses e ficar por herança de patrimônio ao mestrado da mesma Ordem de Cristo." (Gândavo 30) Nesse caso, o ato de nomear não envolve exclusivamente a forma pela qual os sujeitos categorizam e representam a si, o outro e o mundo, mas um exercício de poder. Não é qualquer sujeito que poderia praticar a ação de nomear lugares e sujeitos, apenas os que possuíam o prestígio social de descobridores. A defesa do nome Santa Cruz, portanto, era uma defesa do direito de posse português sobre a região do Atlântico Sul. 


\section{The Principal Navigations, Voyages, and Traffiques of the English Nation}

A carta de patente do rei Henry VII a João Caboto e seus filhos foi publicada na íntegra tanto em latim quanto em inglês no primeiro livro de Richard Hakluyt, Divers Voyages Touching the Discoveries of America (1582) e relatos sobre suas expedições marítimas foram publicadas na coletânea de viagem, The Principal Navigation, Voyages and Traffiques of the English Nation (1589-1600), visando projetar a viagem de Caboto como um exemplo expansionista a ser seguido no atual contexto sociopolítico: "Cabot voyages [was] an example of maritime endeavor and Cabot's claims to territories in the Americas could be used to justify England's right to those lands." (LewisSimpson; Pope 27) Os Cabotos descobriram as Newfoundland e Saint John Island, navegaram pelas costas do Brasil e Flórida e buscaram uma passagem ao Norte para o Oriente representando, assim, o início da história da presença inglesa nas Américas.

Esta coletânea apresenta textos de diferentes gêneros como o intuito de mostrar ao público-alvo que as nações europeias estavam engajadas politicamente na expansão marítima enquanto a Inglaterra não possuía qualquer projeção no Novo Mundo, mesmo depois de anos de descoberto o novo continente, "since the first discovery of America, after so great conquests and plantings of the Spaniards and Portuguese, we of England could never have the grace to set fast footing in such fertile and temperate places as are left as yet unpossessed of them." (Hakluyt 1850 [1582], 8) Como Henry VII e Henry VIII haviam eliminado possíveis sucessores ao trono da dinastia York e a rainha católica, Mary I, ameaça à autonomia política e religiosa inglesa, já havia morrido, o reinado de Elizabeth I se configurava como um período de estabilidade política e, por isso, um momento no qual a rainha poderia pleitear um lugar no novo continente descoberto.

Todavia, a rainha não apresentava, a princípio, uma política expansionista intensa como desejavam os comerciantes ingleses e como a iniciada pelo seu avô, Henry VII, que equipou a esquadra de Caboto 
em busca de um caminho a Norte para as Índias, como afirma a carta de Pedro Ayala dirigida às autoridades espanholas, em 1498:

The King of England has equipped a fleet to explore certain islands [which] set out last year from Bristol in search of the same have discovered. I have seen the map made by the discover, who is another Genoese like Columbus, which has been in Seville and at Lisbon seeking to obtain person to aid him in this discovery (...). The people of Bristol have equipped two, three and four carvels to go in search of the islands of Brazil and the Seven Cities." (Williamson 1928, 39)

Ayala afirma que o rei inglês equipou a esquadra de João Caboto para que o capitão realizasse as mesmas viagens que os ibéricos no novo continente e que, além disso, ele havia percorrido cidades da Espanha e de Portugal em busca de marinheiros experientes que pudessem participar da sua viagem, recorrendo assim, a "mão-de-obra" e a conhecimentos marítimos. As viagens do capitão se estenderam a outras regiões, como o Brasil e as Sete Cidades. As Sete Cidades era uma referência mitológica a regiões ricas em ouro que existiam em zonas para além da Europa e tal mito foi fomentado durante o período das grandes navegações: "Plato spoke of the mysterious civilizations of Atlantis and the island of Antilhas, or the Seven Cities, located beyond the Pillars of Hercules." (Brink 2007 apud Hoig 2013, 14) O projeto expansionista inglês no Atlântico Sul teve continuação no reinado do rei Henry VIII que estabeleceu relações comerciais no Brasil, assim como navegou em diversas regiões das Índias Ocidentais: "[In] the triumphant reign of King Henry VIII (...) arise the first English trade to Brazil, the first passing of some of our Nation in the ordinary Spanish fleets to the West Indies." (Hakluyt 2010 [1589], 406)

A oblíqua presença em expedições exploratórias fez com que outras nações europeias, especialmente Portugal, Espanha e França tivessem maior projeção política no continente. Tal projeção também se fazia presente no cenário literário como bem ilustra Hakluyt na dedicatória do primeiro volume da coletânea, The Principal Navigations (1589). $\mathrm{O}$ clérigo-editor relata que durante sua estadia na França como 
secretário do embaixador Edward Stafford, ele leu diversos livros e ouviu sobre expedições ultramarinas, mas que não havia encontrado nada a respeito das viagens inglesas: "I both heard in speech and read in books other nations miraculously extolled for their discoveries and notable enterprises by sea, but the English of all other for their sluggish security, and continual neglect of the like attempts." (397)

A ausência de literatura sobre empreitadas marítimas inglesas era consequência da "negligência" do reino frente ao novo contexto político-econômico da era das navegações e, principalmente, com o passado expansionista inglês: "it cannot be denied [that] in former ages [English sailors] have been men full of activity and researchers of the remote parts of the world". (Hakluyt 1589, 5) Tal negligência teve consequência na formação dos navegantes, que, na sua maioria, conheciam mais as rotas marítimas de regiões vizinhas ao reino do que as rotas para o Atlântico e Pacífico: "Most of navigators at this time be (for want of trade and practice that way) either utterly ignorant or meanly skillful in the true flat of the Seas, Shoulds, and Islands lying between the north part of Ireland and of Scotland." (s/n)

Diante deste cenário, Hakluyt acredita que os ingleses deveriam "levantar âncoras" em prol de viagens tão lucrativas quanto as dos ibéricos - "Now it is high time for us to weigh our acre, to hoist up our sailed, to get clear of these boisterous, frosty, and misty seas, and with all speed to direct our course for the mild, lightsome, temperate, and warm Atlantic Ocean, over which the Spaniards and Portuguese have made so many pleasant prosperous and golden voyages" (s/n) - e com isso, restaurar seu "compromisso com a descoberta [e exploração] das Américas [desde as viagens] de Caboto." (Imes 80)

O primeiro passo para "levantar âncoras" seria comercializar e tomar posse de regiões não descobertas ou não colonizadas. Hakluyt cita conversas com pilotos portugueses para provar que haviam regiões descobertas que não eram ocupadas e nem possuíam fortificações: 
The Acores, Madera, Arguin, Cape Verde, Guinea, Brasill, Mozambique, Melinde, Zocotora, Ormus, Diu, Goa, Malaca, the Malucos, and Macao upon the coast of China. I say by the confession of singular expert men of their own nation (whose names I suppress for certain causes) which have been personally in the East Indies, \& have assured me that their kings had never above ten thousand natural borne Portuguese (their slaves excepted) out of their kingdom remaining in all the aforesaid territories" (The Life of Sir Walter Raleigh, 1806)

I had great conference in matters of Cosmography with an excellent learned man of Portugal, most privy to all discoveries of his nations who wondered that those blessed countries from the point of Florida Northwards were all this while unplanted by Christians (...).

Moreover, he added that João de Barros, the chief Cosmographer, being moved with the like desire, was the cause that Brasilia was first inhabited by the Portuguese, where they have nine baronies or lordships, and 30 engines or sugar mill, two or three hundred slaves belonging to each mill, and a judge and other officers and a church: so that every mill is as it were little commonwealth and that the country was first planted by such men as for small offences were saved from the rope. (Hakluyt 1592, 10)

Os "singulares peritos portugueses" informaram ao clérigo-editor que as Índias portuguesas não possuíam mais de "dez mil portugueses nascidos com exceção dos escravos", 3 (Hakluyt 1592, 10) o que implica que estas regiões da Ásia e América não eram efetivamente ocupadas, possuindo, assim, um contingente de escravos superior ao de colonos. Considerando que os informantes portugueses revelam segredos políticos, acreditamos que a escolha do verbo confessar é motivada, dado que o relato do português não envolvia exclusivamente a descrição da sua viagem às Índias portuguesas, mas o compartilhamento de informações mantidas em sigilo pelo reino lusitano. A confissão do piloto (confession) confere autoridade a Hakluyt para dizer (say) que a Ásia e a América portuguesas não eram ocupadas.

3. Tradução nossa. 
Segundo o piloto, João de Barros relata na sua obra que o Brasil possuía apenas nove capitanias, trinta engenhos de açúcar, trezentos escravos, um juiz, uma igreja e alguns oficiais. A descrição da quantidade de capitanias (nove), de igrejas (uma) e de engenhos (trinta) apontam que a região não era habitada efetivamente pelos portugueses, dada a inexistência de uma organização social, política e religiosa na região. Além disso, a referência exata quanto ao número de escravos, a referência imprecisa quanto a quantidade de oficiais (alguns) indicam que estes portugueses apenas foram os primeiros a "habitar" e a "plantar" engenhos na província ("Brasilia was first inhabited by the Portuguese; the country was first planted by such men"), mas não os primeiros a estabelecerem uma colonização/ocupação efetiva da região, pois caso tal política administrativa tivesse sido implementada, haveria um número de colonos superior ao número de escravos. (300)

As informações dos "singulares peritos portugueses", do "excelente piloto português" e do "principal cosmógrafo" do reino quanto à vacância na América portuguesa, reforçavam a ideia defendida por Hakluyt quanto a um posicionamento expansionista por todo o continente americano. Os portugueses foram os "primeiros" a descobrirem esta região, mas outra nação, como a Inglaterra, poderia ser a "primeira" a de fato colonizar e tomar posse desta região assim como poderia ser a "primeira" nação a descobrir uma passagem para as Índias pelo Norte: "We might not only take possession of that good land, but also, in short space, find out that short and easy passage by the Northwest." (10)

A proposta de tomar posse do Brasil é apresentada na obra Discourse of the Commodity of the Taking of the Straight of Magellanus (1584). Hakluyt afirma que se as Índias Orientais e Ocidentais caíssem nas mãos dos espanhóis, os ingleses, assim como os povos destas regiões, ficariam impossibilitados de comercializarem uns com os outros e, para evitar que isto acontecesse, a rainha deveria estabelecer uma postura mais agressiva neste cenário transoceânico, 
1. The Straight of Magellanus be taken and fortified, inhabited and kept

2. That the Island of Saint Vincent in Brazil and the soyle adjoining be taken and kept

3. That the Northeast trade be discovered all speed and drawn to trade (Hakluyt 2010, 140)

O Estreito de Magalhães deveria ser ocupado e fortificado por ser a principal "porta de entrada" das riquezas das Índias Orientais e Ocidentais e um dos símbolos de soberania no cenário de disputa transoceânica. São Vicente também deveria ser ocupado pelos ingleses por estar geograficamente próximo ao estreito e por não possuir sequer um contingente militar:

Straight of Magellanus is the gate entry into the treasure of both the East and West Indies. And whatsoever is Lord of this Straight may account himself Lord of the West Indies. [There is] great plenty of wood on both sides; victual and raw flesh offered by the Savages at the Straight to our men (...).The island of Saint Vincent is easily to be won with men, it is neither manned nor fortified and being won, it is to be kept with (...). (Ibidem)

Baseado em relatos de ingleses que navegaram pela costa brasileira, Hakluyt afirma que a província possuía suprimentos suficientes para alimentar multidões de pessoas, um solo favorável para se plantar diversos tipos de sementes, assim como abundância de rios, peixes e madeira de boa qualidade para construir casas e navios. Para assegurar uma posse desta rica região, o pirata Clerke, "a man skilfull in fortification", deveria ser enviado à província, com a promessa de perdão dos seus crimes, para estabelecer fortes na região sem qualquer concessão de documento oficial que comprovasse o envolvimento direto do reino nesta ação, "not with the countenance of the English state". (2010, 140)

Taylor (2010) acredita que a ocupação de São Vicente tornaria esta região um ponto de abastecimento para os ingleses assim como uma fonte de suprimentos para uma possível colônia no Estreito e que a utilização de criminosos na implementação de colônias era uma forma 
de garantir uma primeira ocupação inglesa na região: "English criminals and undesirables could be sent out as colonialists and even if they seized the reigns of the government of the new community, the Strait would be still be in friendly and not enemy hands." (18) Dado a necessidade de "mãos amigas" para iniciar a colonização em São Vicente, Hakluyt sugere que Clerke tenha como exército os povos oprimidos pelos espanhóis, pois estes aceitariam de bom grado lutarem contra seus opressores e serem governados pelos seus aliados, os ingleses.

Esta política de ocupação é projetada pelo clérigo-editor como a forma eficaz de submeter as minas de ouro dos mares do Sul aos ingleses. A ocupação do Estreito de Magalhães e São Vicente em conjunto com a descoberta de uma passagem para as Índias a noroeste, permitiria aos ingleses "cortarem/removerem" definitivamente os espanhóis do comércio das especiarias, e com isso, desmantelar seu prestígio social e econômico na Europa, "cut Spain from the trade of Spices to the abating of his navy, his wealthy and high credit in the world." (Hakluyt 140)

Apesar de os ibéricos serem inimigos políticos e religiosos, a disputa pelo trono português fez com que o reino católico português se aproximasse do reino protestante inglês. Com a morte de Dom Sebastião na batalha de Alcácer-Quibir (1580) e uma possível ascensão de Felipe de Castela ao trono português, a rainha Elizabeth I apoia a sucessão de António Prior do Crato, neto do rei D. Manoel I. Esta proximidade de interesses políticos entre Inglaterra e Portugal contra um inimigo em comum permitiu um intercâmbio de informações portuguesas sobre o Novo Mundo. Hakluyt afirma que Thomas Griggs deveria participar deste projeto de colonização do Estreito e de São Vicente, pois ele já havia viajado para aquela região e convivido vários dias com portugueses, com quem aprendera muitas coisas úteis sobre a região.

Segundo o clérigo-editor, o secretário do rei António Prior de Crato, lhe contou pessoalmente em um encontro em Paris ("told me lately at Paris") que havia poucos soldados nas províncias portuguesas e que muitas destas regiões não possuíam sequer fortes: 
The secretary of Don Antonio King of Portugal, Custodio Leitão, told me lately at Paris that the Portuguese never had in Guinea, Brazil and all the East Indies above 12.000 Portuguese soldiers"; "The island of Saint Vincent is easily to be won with [once] it is neither manned nor fortified (...). Saint Vincent is under the Tropic of Capricorn, 28 degrees and a half from the mouth of the Strait of Magellan. This might be won and possessed by the English." (Hakluyt 2010, 250, 252)

Por ser secretário do rei português, Custódio Leão possuía acesso direto às informações e documentos sobre as províncias, algo extremamente relevante para as ambições expansionistas do clérigo-editor e dos seus patrocinadores. Como estas regiões da Ásia e América "nunca" tiveram contingente militar que oferecesse alguma resistência e o reino de Avis se encontrava em um cenário de instabilidade política, os ingleses deveriam se apressar em tomar posse destas regiões para evitar que "caíssem nas mãos" do rei espanhol: "The Pope's line would shortly disappear and the whole colonial empire of the world, whether it lay East or West, would fall into the single hands of King Philip of Spain." (Taylor 2010, 18)

Como "nas coletâneas de Richard Hakluyt podemos ler uma história da América contada por ingleses, com a intenção de propagar e advogar direitos políticos", (Hue 35) o clérigo-editor projeta os ingleses como os principais agentes da ação de comercializar e ocupar o Brasil e por isso, as ações portuguesas vinculadas a atos de posse como, por exemplo, a chegada de Pedro Álvarez Cabral e o nome Santa Cruz, são apagadas desta história inglesa. O apagamento da agência portuguesa no Brasil permite negar o direito de posse e projetar em primeiro plano as "navegações, viagens e comércio da nação inglesa" no Brasil: 
Certain voyages navigations and traffiques both ancient and of late, to divers' places upon the coast of Brazil: together with a ruttier for all that coast, and two intercepted letters which reveal many secrets of the state of that country: the rest of our voyages to Brazil which have been either intended or performed to the River of Plate, the Strait of Magellan, the South Sea, or farther that way, being reserved for the general heads ensuing (...). (Hakluyt 1600, 18)

No título da seção, o clérigo-editor informa que o corpus textual sobre o Brasil é composto por narrativas de viagens inglesas, cartas interceptadas e roteiros de viagem. O uso de marcadores temporais ("ancient"; "late") aponta que as viagens inglesas realizadas ao Brasil haviam começado no passado e ainda estavam em progresso naquela dada contemporaneidade e, por isso, o clérigo-editor também insere as rotas para chegar a determinadas regiões do Brasil, pois caso a rainha Elizabeth I e os comerciantes desejassem patrocinar mais expedições a esta regiões, e caso alguns nobres e pilotos desejassem participar de tais viagens, eles teriam informações cartográficas sobre as regiões (roteiros) e informações sobre as riquezas locais (cartas e relatos).

Segundo Armitage (1998), como a América e, no caso em questão, o Brasil, não era amplamente conhecido pelo público alvo, o editor precisava utilizar estratégias retóricas para convencê-los a darem continuidade à história inglesa no Brasil: "America [was] previously unknown and unfamiliar to British readers, rhetoric was indispensable for conjuring a striking impression, and hence a persuasive account, of such distant discoveries." (105)

Estas estratégias discursivas também projetariam tentativas frustradas de viagens ao Brasil como parte do rol de viagens inglesas na América do Sul. Tal estratégia já havia sido utilizada pelo editor para convencer a rainha Elizabeth I de não revogar as cartas de patente de Gilbert Humphrey e Walter Gilbert e de convencer os comerciantes a não deixarem de investir em viagens às Américas mesmo que as expedições à Virginia não tenham sido lucrativas. Em um cenário de intensa disputa por territórios do Novo Mundo, e com regiões a serem descobertas e outras que não eram efetivamente ocupadas, a 
rainha deveria conceder mais cartas de patente e não as revogar. Uma possível revogação de carta de patente e a falta de patrocínio real são considerados pelo bispo e geógrafo inglês, George Abbot, uma das razões pelas quais os ingleses não conseguiam estabelecer colônias. Segundo o bispo, os navegantes patrocinavam por conta própria os custos da viagem - "this voyage being enterprised on the charge of private men: and not thoroughly being followed by the state: the possession of this Virginia is now discontinued, and the country is at present left to the old inhabitants." (277)

O escasso patrocínio real não estava restrito apenas à tentativa de colonização da Virgínia, mas à política marítima inglesa durante o reinado elizabetano. Hakluyt enfatiza nos paratextos a relevância do patrocínio real para uma reconfiguração do reino em um contexto de intensa disputa por colônias e especiarias, em especial pelos ibéricos e os franceses estarem realizando viagens pelas mais diversas partes do globo enquanto os ingleses não possuíam qualquer projeção marítima e editorial. Hakluyt ratifica isto ao relatar, na dedicatória da primeira edição da coletânea (1589), que havia lido diversos livros de viagens sobre a Ásia, Américas e África durante sua estadia na França, como secretário do embaixador inglês, e que não havia encontrado um relato sequer sobre expedições inglesas realizadas nestas regiões.

Um intenso patrocínio às empreitadas marítimas pelas mais diversas partes do globo era a única forma de ampliar o corpus textual das "principais viagens, navegações e comércios" da nação inglesa. Como a rainha Elizabeth I financiou a viagem de Sebastião Caboto ao Brasil, por ter sido informada acerca das suas descobertas, um livro sobre a história inglesa nas Américas poderia convencer a rainha e os comerciantes a financiarem mais viagens ao continente americano, em especial, ao Brasil: 
Queen Elizabeth, which being advertised what I had done, entertained me, and at their charges furnished certain ships, wherewith they caused me to sail to discover the coasts of Brazil, where I found an exceeding great and large river named at this present Rio de la Plata" ${ }^{4}$. (...) I give myself to rest from such travels, because there are now many young and lusty Pilots and Mariners of good experience, by whose forwardness I do rejoice in the fruit of my labors, and rest with the charge of this office, as you see. (Hakluyt, 1598 apud Biddel 1831, 10)

Em sua carta, Sebastião Caboto descreve as viagens realizadas pelo seu pai, João Caboto, em nome do Rei Henry VII, até à viagem realizada por ele à costa do Brasil em nome da Rainha Elizabeth. Depois de longos anos ao serviço da Coroa, Sebastião Caboto afirma que chegara o momento de aposentar-se da Marinha e que este espaço vazio no navio seria preenchido por pilotos jovens e experientes. Os relatos de pilotos, de marinheiros e de capitães sobre as suas viagens era importante para a construção de uma história marítima nacional e, por isso, Hakluyt inicia a secção sobre o Brasil com o relato do capitão William Hawkins, o primeiro inglês a esreitar relações de cariz político com os nativos.

Hakluyt apresenta o autor da viagem ao Brasil, William Hawkins, como um homem "sábio", "experiente" e "principal capitão" da Marinha inglesa. O "sábio" capitão percebera que a Inglaterra não poderia continuar na sua insularidade marítima frente a um novo contexto econômico desencadeado com a descoberta do Novo Mundo e a travessia do Cabo da Boa Esperança. O alicerce econômico da nação também não poderia continuar restrito ao comércio com nações vizinhas ("voyages only to the known costs of Europe"), mas pautado na exploração das matérias-primas e especiarias das terras recém descobertas. Em virtude disso, o capitão financia por conta

4. A Discourse of Sebastian Cabot Touching his Discovery of Part of the West India out of England in the Time of King Henry the Seventh, Used to Galeacius Butrigarius the Popes Legate in Spaine, and Reported by the Sayd Legate in this Sort. Disponível em http://www.perseus.tufts.edu/hopper/text?doc=Perseus\%3Atext\%3A1999.03.0070\%3Anarrative\%3D582. Data de acesso: 26/04/1986. 
própria uma viagem ao Brasil, algo "naqueles [tempos] muito raro especialmente para a nação inglesa". $(1600,700)$

Esta descrição inicial sobre o capitão e as suas motivações é mediada por Hakluyt, pois se o editor desejasse reproduzir fielmente as palavras proferidas ou escritas por Hawkins, Hakluyt teria usado verbos discenti no início de algumas orações para sinalizar que determinados comentários e opiniões eram da responsabilidade do narrador da viagem e não sua. A estrutura do relato de Hawkins assim como de outros na coletânea indicam uma inter-relação do clérigo-editor com o evento narrado, como os sujeitos participantes da ação e o público para o qual este texto era projetado.

Uma das exigências do gênero discursivo, relato de viagem, é o texto na primeira pessoa gramatical, uma vez que a veracidade reside no contato direto entre o narrador e os eventos descritos. Contudo, há muitos relatos que não obedecem a tal regra e que poderiam invalidar, de certa forma, a proposta editorial de Hakluyt de construir uma história da nação baseado na memória dos navegantes. O clérigo-editor afirma nos paratextos que sua familiaridade com comerciantes e navegantes lhe permitiu ter acesso direto aos seus relatos, sendo ele, neste contexto, um intermediário e porta-voz dos navegantes e comerciantes que estiveram para além dos pilares de Hércules. Hakluyt, porém, não descreve mecanicamente as ações realizadas e observadas por Hawkins, mas infere opiniões nos textos.

Hakluyt afirma no prólogo ao leitor (1589) que atribui cada narrativa ao seu autor, aquele que realizou e escreveu sobre as viagens: "I have referred every voyage to the author, which both in person has performed and in writing has left the same." (s/n) Todavia, estas narrativas não apresentam unicamente a "voz" do autor da viagem, mas a "voz" do clérigo-editor que deixa marcas tanto no título do relato quanto no corpo do texto quanto a sua ação de querer convencer o público-alvo de que não fazia mais sentido continuar a navegar apenas "pelas costas conhecidas da Europa", mas sim, navegar pela costa brasileira, "algo raro naqueles dias para nossa nação". (Hakluyt 1600, 700)

As viagens ao Brasil eram raras para os ingleses, mas frequentes entre os franceses. Mesmo excluídos do Tratado de Tordesilhas, os franceses 
já haviam realizado diversas viagens ao Brasil, e por realizarem diversas viagens ao Atlântico Sul, muitos relatos franceses circulavam pela Europa e serviram de fonte de informação sobre o Brasil. Capítulos do livro de Jean de Léry, de entre outras narrativas francesas, foram incluídas na seção "Brasilia", na obra do editor holandês Jan van Lischoten Itinerario: Voyage ofte schipvaert van Jan Huyghen van Linschoten naer Oost ofte Portugaels Indien, 1579-1592 (1596) que posteriormente fora traduzida para o inglês, John Huighen van Linschoten, His Discours of Voyages into ye Easte and West Indies (1598) e incorporada na terceira edição da coletânea de viagem de Richard Hakluyt, The Principal Navigations (1600). O extrato do livro de Jean de Léry também foi compilado na coletânea de Samuel Purchas na seção dedicada às viagens inglesas pelo Brasil, Hakluyt Posthumus or Purchas his Pilgrimes (1625).

\section{Considerações Finais}

Procurámos analisar as obras de Pero Gândavo e Richard Hakluyt de uma perspectiva diferente daquelas que classificam tais obras, respectivamente, como "propaganda de emigração", (Abreu 2008) "literatura de informação" (Bossi 2006) e "prosa épica da moderna nação inglesa". (Froude 1852) Acreditamos que estas obras sejam uma "arena de disputa" pelos metais preciosos e especiarias dos novos mundos descobertos. A disputa política pelas terras americanas também se fez presente no cenário discursivo, desencadeando, assim, a publicação das obras de Richard Hakluyt e Pero Gândavo naquele momento histórico.

Hakluyt (1598) compilou as "antigas e recentes" viagens inglesas com o intuito de desenterrar do profundo silêncio a história marítima inglesa, "to bring Antiquities smothered and buried in dark silence to light, and to preserve certain memorable exploits of late years by our English nation achieved" (2) e para instruir futuros navegantes e comerciantes do reino, "things might be gathered which might commend our nation for their high courage and singular activity in the search and discovery of the most unknown 
quarters of the world."(2) Gândavo também visava "desenterrar do profundo silêncio" notícias sobre a província americana em Portugal: "creio que esteve sepultada em tanto silêncio mais pelo pouco caso que os portugueses sempre fizeram da mesma província, que por faltarem em Portugal pessoas de engenho e curiosa." (37)

Os dois editores afirmam que assumiram tal tarefa, pois até áquele momento, ninguém havia escrito uma história da nação nas Américas, "seeing no man to step forth to undertake the recording of so many memorable actions, but every man to follow his private affairs;" (2) "a causa principal que me obrigou a lançar mão da presente história e sair com ela à luz foi por não haver até agora pessoa que empreendesse, havendo já setenta e tantos anos que esta província foi descoberta." (37)

Considerando que "comunicar é agir", (Fiorin 2007, 74) a escrita sobre o Brasil também era uma forma destes editores "agirem" no cenário editorial e político em questão dada a insatisfação de ambos com o posicionamento dos seus reinos em relação ao continente americano. Depois de "setenta anos de descoberta a província", os portugueses não haviam se dedicado à região e, por isso, o nome Santa Cruz, ato de posse português, não havia prevalecido, mas sim o nome do "pau que tinge panos", o nome Brasil. O apagamento da agência portuguesa no nome da província também se fazia presente na história da mesma, pois a política de sigilo sobre as regiões descobertas inviabilizou a circulação de informação entre os próprios portugueses. Por não saberem da existência da província ou das riquezas naturais e minerais, não havia pessoas para desenvolverem uma ocupação efetiva da região.

Para Hakluyt, a Coroa precisava assumir uma postura expansionista mais ativa e agressiva, pois "since the first discovery of America, after so great conquests and plantings of the Spaniards and Portuguese", (Hakluyt 1582, 8) os ingleses não "se lançaram" às regiões não ocupadas pelos ibéricos, como podia ser notado na ausência de literatura de viagem inglesa. ${ }^{5}$ Havia chegado o tempo dos ingleses se inserirem,

5. "I both heard in speech and read in books other nations miraculously extolled for their discoveries and notable enterprises by sea, but the English of all other for their sluggish security, and continual neglect of the like attempts." (Ibidem) 
de fato, no cenário transoceânico para compartilharem com os ibéricos as riquezas do Novo Mundo: "I conceive great hope that the time approached and now is, that we of England may share and part stake (if we will ourselves), both with the Spaniard and the Portuguese, in part of America and other regions, as yet undiscovered." (Hakluyt 1582, 8)

\section{Bibliografia}

Armitage, David. "Literature and Empire". The Oxford History of the British Empire, I: The Origins of Empire. Ed. Nicholas Canny. Oxford: Oxford University Press, 1998.

---. "The Elizabethan Idea of Empire". Transactions of the Royal Historical Society, 2004, vol. 14, 269-277.

Barros, João de. Ásia. Décadas I-IV. (fac-símile da quarta edição revista e prefaciada por António Baião). Lisboa: Imprensa Nacional /Casa da Moeda, 1988.

Borba, Francisco. Dicionário de Usos do Português do Brasil. São Paulo: Ática, 2002.

Bosi, Alfredo. História Concisa da Literatura Brasileira. São Paulo: Cultrix, 2006 (1936).

Brito, Cristiana. "Gândavo's Sea Monster and Transfer of Nature Knowledge in the 16 ${ }^{\text {th }}$-Century Europe". New Science from Old News. Lisboa: SIG, 2006. 37-71.

Curcino, Luzmara. "Velhos Novos Leitores e suas Maneiras de Ler em Tempos de Textos Eletrônicos". Estudos Linguísticos, vol. 41, n³3, 2012. 1013-1027.

Daniels, Christine e Michael Kennedy. Negotiated Empires: Centers and Peripheries in the Americas, 1500-1820. New York: Routledge, 2002.

Delmas, Adrien. "L'écriture de l'histoire et la compétition européenne outre-mer au tournant du XXII ${ }^{e}$ siècle." L'Atelier du Centre de recherches historiques, vol.7, 2011. Disponível em: http://journals.openedition.org/acrh/3632.

Dicionário da Língua Portuguesa Contemporânea da Academia de Ciências de Lisboa. Lisboa: Editorial Verbo, volume II (G-Z) 2001. 2910.

Duarte, Maria Eugênia. "A Expressão da Modalidade Deôntica e Epistêmica na Fala e na Escrita e o Padrão SV". Revista do GELNE, vol. 14, 2012. 77-94.

Fiorin, José. Linguagem e Ideologia. São Paulo: Ática, 2007. 
França, Jean Marcel de Carvalho. A Construção do Brasil na Literatura de Viagem: Antologia de Textos 1591-1808. Rio de Janeiro: UNESP José Olympio, 2012.

Froude, James Anthony. "England's Forgotten Worthies". The Westminster Review, vol.58, 1852.

Gândavo, Pero de Magalhães. A Primeira História do Brasil. História da Província Santa Cruz a que Vulgarmente Chamamos Brasil. Notas de Sheila Hue e Ronaldo Menegaz. Brasília: Conselho Editorial do Senado Federal, 2004.

---. Tratado da Terra do Brasil. História da Província Santa Cruz que Vulgarmente Chamamos Brasil. Brasília: Conselho Editorial do Senado Federal, 2008.

Goff, Jacques Le. História e Memória. Trad. Bernardo Leitão. Campinas: Editora UNICAMP, 1996.

Guzauskyte, Evelina. Christopher Columbus' Naming in the Diarios of the Four Voyages (1492-1504). Toronto: University of Toronto Press, 2014.

Hakluyt, Richard. Divers Voyages Touching the Discovery of America. London: Hakluyt Society, 1850 (1582).

---. The Discovery of Muscovy. London: Cassile \& Company, 1889 (1589).

---. The Original Writings \& Correspondence of the Two Richard Hakluyts. Ed. Eva Taylor. London: Hakluyt Society, 2010.

---. The Principal Navigations, Voyages and Traffiques of the English Nation. Catálogo on-line. Obras Raras. Kraus Collection of Sir Francis Drake (Biblioteca Nacional do Congresso Americano). Disponível em: http://memory.loc.gov/ cgi-bin/query/h?intldl/rbdkbib:@field(NUMBER+@band(rbdk+d0301)).

---. The Principal Navigations, Voyages and Traffiques of the English Nation. Adelaide: University of Adelaide, 2014. Disponível em: https://ebooks.adelaide.edu. $\mathrm{au} / \mathrm{h} /$ hakluyt/voyages/.

Hue, Sheila Moura. "Ingleses no Brasil: Relatos de Viagem 1526-1608". Anais da Biblioteca Nacional. Rio de Janeiro: Biblioteca Nacional, 2006, vol.126.

Hoig, Stan. Come Men on Horse. The Conquistador Expedition of Francisco Vásquez de Coronado and Don de Oñate. Colorado: University of Colorado Press, 2013.

Holanda, Sérgio Buarque da. Visões do Paraíso: os Motivos Edênicos no Descobrimento e Colonização do Brasil. São Paulo: Editora Brasiliense, 2000.

Imes, Robert. Travel Compilation in Sixteenth Century England: Eden and Ramusio as Hakluyt's Generic Precursors. Master's Thesis of the Department of English and Film Studies. University of Alberta, 2012. 


\section{ESTUDOS / ESSAYS}

Jauss, Hans Robert. A História da Literatura como Provocação à Teoria Literária. Trad. Sérgio Tellaroli. São Paulo: Ática, 1994.

Lewis-Simpson, Shanon e Peter Pope. Exploring Atlantic Transitions. Woodbridge: Boydell Press, 2013.

Popelinière, Lancelot Voisin de La. Les Trois Mondes. Paris, 1582. Disponível em: https://archive.org/details/LesTroisMondes.

Rajagopalan, K. Por uma Linguística Crítica. Linguagem, Identidade e a Questão Ética. São Paulo: Parabola Editorial, 2003.

Sousa, Gabriel de Soares. Tratado Descritivo do Brasil em 1587. Edição Francisco Adolfo de Varnhagen. Rio de Janeiro: Typografia Universal de Laemmert, 1851.

Todorov, Tzvetan. A Conquista da América: a Questão do Outro. Trad. Beatriz Perrone Moisés. $2^{\text {a }}$ Ed. São Paulo: Martins Fontes, 1999. 